\title{
Aktuelles aus den Arbeitskreisen
}

Zwei überarbeitete neue Informationen zu den Thematiken „NIPT - Nicht-Invasiver pränataler Trisomie Test“ und „Klinische Anwendung der Array-CGH (Microarrays, „Genchips“) in der Pränataldiagnostik" haben die Autoren M. Schmid (Univklinik f. Frauenheilkunde,MedUni Wien), B. Pertl (Pränatalzentrum Graz Ragnitz, MedUni Graz) und M. Speicher (Inst. f. Humangenetik, MedUni Graz) aus dem AK Gynäkologie/Geburtshilfe verfaßt, die in der Vollversion auf der Website des AK in der Rubrik „Aktuelles/Publikationen“ zum Download bereit stehen (www.oegum.at/arbeitskreise/

gyngeburtshilfe.html). Die Zusammenfassungen und die thematischen Gliederungen der beiden Dokumente finden Sie im folgenden abgedruckt:

Der Nicht-Invasive pränatale Trisomie Test (NIPT) - Analyse der zellfreien DNA (cfDNA) im mütterlichen Blut zum Screening für fetale Aneuploidien

\section{$\nabla$}

von Maximilian Schmid, Barbara Pertl, Michael Speicher

\section{Zusammenfassung}

Der nicht-invasive pränatale Trisomie Test (NIPT), auch zellfreier DNA-Test genannt, ermöglicht eine zuverlässige Beurteilung des Risikos für häufige Chromosomenstörungen beim Feten. Der Test beruht auf der seit längerem bekannten Tatsache, dass im mütterlichen Blut genetisches Material (i.e. zellfreie DNA) der Mutter als auch des Feten vorhanden ist. Dieses wird mittels hochentwickelter Labormethoden (Next Generation Sequencing, Microarray Analyse) untersucht. Über Messung der Konzentration und Verteilung der zellfreie DNA wird eine Einschätzung abgeleitet, ob das ungeborene Kind von einer Chromosomenstörung betroffen sein könnte oder nicht.
Diese neue Untersuchungsmethode kann ab der 11. Schwangerschaftswoche durchgeführt werden. Sie hat durch ihre hervorragende Sensitivität und Spezifität, insbesondere als Screening-Test für die Trisomie 21 (Down Syndrom) eine höhere Aussagekraft als der Combined Test. Zu beachten ist dabei, dass es sich um einen medizinischen Test, nicht aber um ein medizinisches Diagnoseverfahren handelt. Es kann also auch beim zellfreien DNA-Test selten zu falsch unauffälligen und falsch auffälligen Befunden kommen. Darüber hinaus wird meist nur auf das Vorliegen einer freien Trisomie 21 (Down Syndrom), Trisomie 18 (Edwards Syndrom) und Trisomie 13 (Pätau Syndrom) untersucht. Eine zytogenetische Diagnostik aller 46 Chromosomen des Feten ist also weiterhin nur nach einem invasiven Eingriff (Amniozentese, Chorionzottenbiopsie) möglich.

Derzeit beschränkt sich der Einsatz von zellfreien DNA-Tests, primär aus ökonomischen Überlegungen, auf die Anwendung als sekundäres Screening nach auffälligem Combined Test. Insgesamt scheint es jedoch wahrscheinlich, dass in Zukunft zellfreie DNA-Tests vermehrt als primäre Screening-Methode auf häufige Chromosomenstörungen eingesetzt werden.

Weiterer Inhalt: Zellfreie DNA im mütterlichen Blut; Screening auf Aneuploidien durch Analyse der zellfreien DNA im mütterlichen Blut; Vorteile von NIPT; Limitationen von NIPT; NIPT bei Mehrlingsschwangerschaften; Erweiterung des NIPT Untersuchungspanels; NIPT zum Screening nach Aneuploidien der Geschlechtschromosomen; Einsatz von zellfreien DNA-Tests in der klinischen Praxis | Zukunft der Analyse der zellfreien DNA im mütterlichen Blut; Literatur, PDF unter: AK Gyn/Geburtshilfe: www.oegum.at
Klinische Anwendung der ArrayCGH (Microarrays, "Genchips") in der Pränataldiagnostik $\checkmark$

von Maximilian Schmid, Barbara Pertl, Michael Speicher

\section{Zusammenfassung}

In den letzten Jahren haben sich die Methoden der genetischen Analyse rasant weiterentwickelt. In der Pränataldiagnostik ist die klassische Chromosomenanalyse durch ein weiteres Verfahren mit einem deutlich besseren Auflösungsvermögen, der sogenannten „Array-CGH“ (engl.: comparative genomic hybridization, $\mathrm{CGH}$; deutsch: vergleichende genomische Hybridisierung) ergänzt worden. Die ArrayCGH ist in der Lage, auch sehr kleine Verluste (sogenannte „Deletionen“) oder Gewinne (sogenannte „Duplikationen“) an Chromosomen nachzuweisen, die mit der herkömmlichen Chromosomenanalyse nur schwer oder gar nicht erkannt werden 
können. Diese numerischen Veränderungen werden auch Kopienzahlvarianten (engl.: copy number variations [CNVs]) genannt. Der große Vorteil der Array-CGH besteht im verbesserten Auflösungsvermögen, ein Nachteil ist jedoch, dass die Bedeutung von CNVs nicht in allen Fällen leicht zu bestimmen ist. Trotzdem wird erwartet, dass die Array-CGH die konventionellen zytogenetischen Verfahren in der Pränataldiagnostik in naher Zukunft ablösen werden.

weiterer Inhalt: Hintergrund; Methode; Anwendung in der Pränataldiagnostik, 